\title{
Why is COVID-19 killing more African Americans than Whites in the United States?
}

\author{
Soma Hewa \\ School of Policy Studies, Queen's University, Kingston, Ontario, Canada, and School of Public Administration, Guangzhou \\ University, Guangzhou, China.
}

Correspondence: Professor Soma Hewa

e-mail: hewas@queensu.ca

(D) https://orcid.org/0000-0002-0887-8550

\begin{abstract}
A social gradient in mortality and morbidity exists within countries owing to structural inequalities. Disease and health are not neutral to social, political, and economic relations, but they interact, and the human body is the stage on which these social contradictions are played out.
\end{abstract}

Keywords: African Americans, COVID-19, health disparities, institutionalized racism.

\section{Introduction}

Across the United States, African Americans are disproportionately affected by the COVID-19 pandemic. As of May 1, 2020, according to the official website of U.S. Centers for Disease Control and Prevention (CDC), the total number of reported COVID-19 cases had surpassed one million, while the total number of deaths had reached 63,000 . Of these nationwide cases for which race were identified, 30 percent were African Americans, despite the fact that they represent only 13 percent (43 million) of Americans. In some states, such as Mississippi, Georgia, Louisiana, and Alabama, over 50 percent of reported cases were African Americans (1). The large number of deaths has overwhelmed African American communities across the United States. The disease is still spreading, and by the time the infection is brought under control these figures could be much higher. This review is a critical reflection on the current crisis of COVID-19 in North America, and its impact on African Americans across the United States.

\section{COVID-19 preying on the vulnerable}

In the United States, there is a saying: "when Americans sneeze, African Americans catch pneumonia." There is a truth to this adage: it has been shown over and over again that African Americans are the least healthy segment of the US population. To understand the overwhelming health disadvantage of African Americans, it is critically important to understand the historical context of the African American population in which the social determinants of health have been shaped, and continue to be shaped. As a racial minority, they have experienced institutionalized racism since the time of slavery, and institutionalized racism, discrimination, and social injustice persist to date in almost all spheres of their lives that foster toxic physiological stress (2). The African American health disadvantage is a reflection of these various structural inequalities that have endured (3). For any measure of health, African Americans fare poorly compared to white Americans (4). It has been known for decades that African Americans have significantly lower life expectancy at birth (75 years), compared to white Americans (79 years). Infant mortality is 11.3 for African 
Americans, compared to 4.9 for white Americans, per 1,000 live births. For maternal mortality, according to the National Center for Health Statistics, African American mothers fared the worst, dying 2.5 times more often than white American mothers (37.1 vs. 14.7 deaths per 100,000 live births). African Americans have worse outcomes than white Americans for almost all cancers at every stage of the disease (5). African Americans suffer disproportionately from cardiovascular diseases, hypertension, diabetes, asthma, and obesity.

The COVID-19 pandemic has exposed that, as in any catastrophe, it is those who live on the margins of society who suffer the most. Low-income communities with high rates of unemployment, overcrowded and substandard housing and a longstanding history of institutionalized racism have experienced the highest rate of infection and death from COVID-19 in many countries. Many of these communities also have the highest number of individuals with metabolic diseases and other debilitating illnesses, which have left them less able to fight any new infection on their own. The pandemic has brought to light, among other things, the existing deep-seated structural disparities along race and class lines. Yet, the public discourse and the mainstream media "sanitize" these social ills with carefully crafted language emphasizing the pathophysiology of the infected individuals, thus glossing over social reality. For example, those who have been disproportionately affected by COVID-19 are often referred to, as people with "preexisting conditions," in the language of the medical insurance industry in the United States. These "preexisting conditions" are invariably clinical conditions, such as diabetes, hypertension, obesity, asthma, and suppressed immune systems, even though these preexisting medical disorders are generally preceded by certain social structural disorders. By naming them merely as "preexisting medical conditions" we lay the blame at the feet of individuals and fail to question the structural social injustices that engender these problems in the first place. When do existing social structural conditions become "preexisting medical conditions"? Why do we refer to illnesses as "preexisting conditions," instead of referring to their underlying socio-economic causes? Could the pandemic of COVID-19 be an opportunity to redress the existing socio-economic inequalities and social injustices?
In population health, researchers have observed an inverse correlation between socio-economic status and mortality. It has been well documented that even in countries with universal access to healthcare, there is a socio-economic gradient in morbidity and mortality, which points to the evidence that there are factors in the socio-economic systems that affect health. Although this social gradient in health exists in all societies, it is particularly acute in societies with wider socio-economic disparities reinforced by powerful ideologies such as race, gender, class, and caste. In affluent societies, it is not one's absolute income that affects health and illness; rather, it is one's relative income that is crucially important for health. The countries with similar income levels, but relatively lower level of income inequality, have lower morbidity and mortality rates compared to those with greater income inequalities. This particular trend in income vis-à-vis mortality and morbidity rates has led researchers to explore more closely the importance of social status, social cohesiveness, and structural social inequalities for people's sense of belonging, mutual respect and the overall health and psychological well-being. These studies found that after a certain income threshold that fulfill the needs of a basic standard of living of the population, which includes adequate nutrition, running water, indoor toilets, etc., further increases in income, or level of national wealth is less accounted for in overall health. Most importantly, it is at this income threshold that developed and some developing societies undergo an epidemiological transition from predominantly infectious diseases to chronic diseases as the major causes of death. Further, at this point in the economic development of a nation, mortality and morbidity rates become more sensitive to relative income and the overall quality of life, rather than to absolute income. The income disparities affect social relations and social cohesiveness, which manifest as a social gradient in morbidity and mortality. Simply put, people in the lower social echelons perceive their place in society not exclusively in terms of the material wealth but in terms of nonmaterial qualitative status. It becomes an obstacle to their self-realization and autonomy, and a powerful stressor that activates neuroendocrine and immune responses (6). 


\section{Health impact of socio-econmic disparities and institutionalized racism}

While their socio-economic position is a critically important factor in the African Americans' health disadvantages, it alone cannot fully account for them. These disadvantages persist even when controlling for income and education. Researchers have explained this trend in terms of chronic stress engendered by the hostilities of a racist and sexist social environment: "persistent racial differences in health may be influenced by the stress of living in a race-conscious society. These effects may be felt particularly by black women because of "double jeopardy' of gender and racial discrimination." (7). Hostility is known to engender anger, anxiety, and depression, which in turn give rise to coronary heart diseases via neuroendocrine and physiological pathways. Epidemiological research defines hostility as a longstanding attitudinal temperament that tends to influence social interactions, which can be damaging to one's health depending on the intensity and the length of interaction. For people who live in such an environment, it's a lifetime of distress. Numerous studies have shown how fundamental social institutions such as healthcare treat African Americans. A study conducted in 2002 titled Unequal Treatment: Confronting Racial and Ethnic Disparities in Health Care, published by the National Academy of Sciences, found some shocking evidence of racial bias against African Americans in healthcare settings. The report found that African Americans are less likely to receive appropriate cardiac medications; to undergo coronary bypass surgery; to receive less often necessary kidney dialysis and transplants than whites. This often results in higher death rates among African Americans. They are 3.6 times more likely to have legs and feet amputated than whites resulting from diabetes, even when all other factors were equal. The report also found that cesarean sections were 40 percent more likely to be performed on African American women compared to white women (8).

For a vast majority of African Americans, everyday life is an extremely stressful experience owing to institutionalized racism, which reflects on their health status. Stress induced disease, or allostatic load, is the chronic wear and tear on the body resulting from adaptation to a stressor. One of the common outcomes of the adaptation (allostasis) is cardiovascular reactivity resulting in high blood pressure. A chronically elevated blood pressure accompanies several risk factors such as increased blood levels of glucose, low-density lipoprotein, and cholesterol, which are all known clinical risk factors for heart diseases, diabetes, obesity, and strokes. Studies have shown that once the neuroendocrine process raises the blood pressure, and maintains it at a high level for an extended period, blood pressure tends to remain high even if the initial cause of the elevation no longer exists. The brain and arteries develop structural and functional remodelling as part of the adaptation. This remodelling, over time, particularly in connection with arterial constriction, causes damage in the inner lumen of the arterial walls, where atherosclerotic plaques begin to develop, obstructing the blood flow. At this stage, the narrowed arteries with blockages are bound to cause heart attacks and strokes (9). Among the major causes of death and the life expectancy disadvantage for African Americans compared to white Americans are ischaemic heart disease, cerebrovascular disease, and hypertension. For African American women who experience institutionalized racism and sexism along intersectional lines, their health implications are further evidence in the higher rate of infant and maternal deaths due to hypertension and preeclampsia.

Further, under chronic stress, the release of glucocorticoids undermines the production of white blood cells, which has several pathological consequences. During prolonged stress, the suppressed immune system delays the healing of wounds and injuries, and most importantly exposes the organism to various pathogenic agents such as viruses, bacteria, and carcinogenic agents, which are normally removed from the body by the white blood cells. The immune system, particularly the thymus gland and its ability to produce white blood cells, is mediated by glucocorticoids (10). This explains the cruel truth that people with suppressed immune systems are most likely to catch COVID-19, and the typical neuroendocrine and physiological reactions of those living in toxic social environments seem to fit this epidemiological description. The prolonged immune suppression caused by the chronic stress means that individuals may not be able to fight infections, including cancer. 
Likewise, under chronic stress, glucocorticoids impede the insulin function that regulates the blood glucose level. The function of insulin is to remove the extra glucose from the blood and store them in the muscles, body fat, and the liver as glycogen to be utilized when the blood glucose level goes down. During stress, the increased demand for energy to meet an external challenge prevents this insulin activity resulting in abnormally high levels of blood glucose. While elevating blood levels of glucose and free fatty acids, and preventing insulin from storing them in the muscles and the liver, the glucocorticoids promotes the deposition of glycogen in the abdomen. It has been identified that abdominal obesity, as in Cushing's disease, as well as type I and type II diabetes are triggered by chronic stress (11). Recent epidemiological studies have substantiated these observations that excessive metabolic disorders among African Americans are related to the psychosocial stress of living environment. They have shown that structural inequality is positively correlated with obesity rates, diabetes-related mortality rates, and a person's average daily calories intake (12).

Given this general state of health, it is hardly a coincidence that a large percentage of African Americans have become victims to the COVID-19 pandemic.

\section{Conclusions}

The COVID-19 pandemic has overwhelmingly affected the African American population in the United States, but the link between deep-seated social structural conditions and the rapid spread of the pandemic suggests that diseases transmit easily in communities in which the human host is left vulnerable. This particular scenario is not, of course, unique to the United States, but it is all the more interesting and important because the United States is the richest country in the world, and its professed ideology of "equality of opportunity" has been a magnet for millions of new immigrants each year from around the world. Structural inequality, racism, sexism, and all forms of discriminations exist around the world, and these existing social and economic conditions make people susceptible to diseases, rather than the other way around.
Diseases are often symptomatic of a much deeper social malaise, but powerful ideologies prevent people from understanding this reality; particularly the American corporate media, the billionaire-class, and the political elite are oblivious to the impact of structural inequality, and rarely look inwardly to see the true causes of America's health disparities. The presence of the COVID-19 pandemic in the United States highlights these inherent inequalities in American society yet again. Let us hope that this time it may be a catalyst for fundamental structural changes in the future.

\section{References}

1. CDC, Centers for Disease Control and Prevention, Corona Virus Disease 2019, (COVID-19), https://www.cdc.gov/ coronavirus/19-ncov/need-extra-precautions/racialethnic-minorities.html. By the end of May 2020, the number of cases had surpassed 1.5 million while the number of deaths had exceeded 100,000 in the United States.

2. Carlson ED, Chamberlain RM. Allostatic load and health disparities: A theoretical orientation. Research in Nursing \& Health, 2005; 28: 306-15.

3. Villarosa L. Why America's Black Mothers and Babies are in a life-or-death crisis? The answer to the disparity in death rates has everything to do with lived experience of being a Black woman in America. New York Times Magazine, April 11, 2018.

4. Nonan AS, Velasco-Mondragon HE, Wagner FA. Improving the health of African Americans in the USA: an overdue opportunity for Social Justice. Public Health Reviews, 2016; 7(12): 2-20.

5. US Department of Health and Human Services, Office of the Minority Health, https://www.cdc.gov/nchs/data/ nvsr/nvsr68/nvsr68_10-508.pdf

6. Wilkinson RG, Pickett KE. The problem of relative deprivation: why some societies do better than others. Social Science and Medicine, 2007; 65:1965-78; Pickett KE, Wilkinson RG. Income inequality and health: a causal review. Social Science \& Medicine, 2015; 128: 316-26.

7. Arline T, Geronimus TA, Hicken M, Keene D, Bound J. Weathering and Age Patterns of Allostatic Load Scores Among Blacks and Whites in the United States. American Journal of Public Health, 2006; 96: 826-33. 
8. Smedley DB, Stith YA, Alan R. Nelson RA. 2002 Unequal Treatment: Confronting Racial and Ethnic Disparities in Health Care, the National Academy of Sciences. The National Academies Press Washington, DC.

9. McEwen BS, Gianaros PJ. Central role of the brain in stress and adaptation: links to socio-economic status, health, and disease. Annals of New York Academy of Science, 2010; 1186: 190-222; Sterling P, Eyer J. Allostasis: a new paradigm to explain arousal pathology, In: Fisher S, Reason J. (Eds.) Handbook of Life Stress, Cognition and Health, Wiley, New York: 1988; 631-51.

10. Cohen S, Adler N, Alper CM, Doyle WJ, Treanor JJ. Objective and subjective socioeconomic status and susceptibility to the common cold. Health Psychology, 2008; 27: 268-74; Dowdell K, Whitacre C. Coping with the environment: Neural and endocrine mechanisms. Oxford University Press, New York: 2000.

11. Goodman E, Adler N, Daniels ER, Morrison JA, Slap GB, Dolan LM. Impact of objective and subjective social status on obesity in a biracial cohort of adolescents. Obesity Research, 2003;11: 1018-26.
12. Pickett KE, Kelly S, Brunner E, Lobstein T, Wilkinson RG. Wider income gaps, wider waist-bands? An ecological study of obesity and income inequality. Journal of Epidemiology and Community Health, 2005; 59: 670-74; Wilkinson RG, Pickett KE. The problem of relative deprivation: why some societies do better than others. Social Science and Medicine, 2007; 65: 1965-78; Rostand GS, Cliver PS, Goldenberg LR. Racial disparities in the association of foetal growth retardation to childhood blood pressure. Nephrology Dialysis Transplantation, 2005; 20: 1592-97; David R, Collins J. Disparities in Infant Mortality: What's Genetics Got to Do With It? American Journal of Public Health, 2007; 97: 1191-97. 